\title{
VENEREAL DISEASE OF ANIMALS
}

\author{
By DR. R. LOVELL
}

\section{Discussion}

The President said he was sure he was voicing the feelings of all present in expressing to Dr. Lovell their thanks for the paper they had just heard. Those present could scarcely have failed to note many points of similarity between venereal diseases in animals and in man. Dr. Lovell had told them that to stamp out venereal diseases in animals resort could be had to castration or even slaughter. We could not, nor did we even want to, apply those methods to man : but it is certain that had it been known that venereal diseases occurred in animals it must have been seen that there was little foundation or force in the argument that venereal disease in man was a visible tangible punishment for sin. An argument which in the past had blanketed and delayed organised efforts to diminish the incidence of these diseases in man.

Dr. Lovell had discussed, and dismissed as unproven, the theory that the llama might have been the source of human syphilis. He, Dr. Hanschell, first heard about llama syphilis some fifteen years ago. A patient who had wandered for years over and about the Andes consulted him for four small ulcers closely arranged in semi-circle on external surface of left upper arm. Clinically they resembled tertiary syphilitic ulcers; and after the blood tests were found to be strongly Wassermann positive, the diagnosis of syphilis was announced. The patient declared with Olympian calmness (he was very tall and weighed r8o odd pounds) he was not surprised; the ulcers were on the exact site of scars left by a llama bite : it was well known that the llamas had syphilis and often conveyed it to man, and it was known that in old times there had been strict regulations made by the Jesuit missionary fathers that only male llamas could be used for the pack caravans carrying goods across the Andes. Alas, it was also well known, though not to that patient, how easily many men persuaded themselves that their 
venereal disease had come to them otherwise than per copulam.

Dr. D. NABARRo said he was sure all members present felt much indebted to Dr. Lovell for the paper which he had just read. He did not think this subject had previously been presented to the Society.

The disease he, the speaker, was more interested in than in the others referred to was dourine, as he was actively interested in the subject of sleeping sickness in the early days of the investigation of trypanosomiasis. One question in connection with dourine which was not emphasised by Dr. Lovell was its close resemblance to syphilis in many respects. Many years ago Sir Frederick Mott pointed out that some of the spinal cords from cases of dourine sent to him from India showed lesions similar to thcse of syphilis ; Sir Frederick thought the lesions were like those of syphilitic meningitis, and the paralysis which those animals had was much like that seen in humans in late secondary or tertiary syphilis. Dr. Lovell said the parasite was scanty in the blood, and in sleeping sickness this happened often; the parasites were not usually found in the blood, but if one took Io to 20 c.c. and centrifuged it, took off the supranatant fluid, then centrifuged again, trypanosomes were found.

$\mathrm{He}$ asked whether any of the diseases mentioned tonight were transmitted to the offspring. Dr. Lovell had said the diseases were transmitted to the female, or to the male, as the case might be, during coitus, but the speaker formed the idea that none of the diseases were transmitted to the offspring, as syphilis was. He did not know whether it would be possible to send out to America to see whether young llamas were infected. Nor did he know whether rabbits infected with syphilis gave birth to infected progeny.

This had been one of the most interesting papers he had heard; it was off the Society's usual line. He felt very grateful to Dr. Lovell for it.

DR. MARGARET RoRke considered that all the members owed a deep debt of gratitude to Dr. Lovell. Like Dr. Nabarro, she had found it an extremely interesting paper. Though the subject was off the beaten track of members' work, they were all closely associated with animals. She had been particularly interested in trypanœma infection in rabbits, and trichomona infection in cattle. 


\section{BRITISH JOURNAL OF VENEREAL DISEASES}

Dr. Rorke said she appreciated very much what Dr. Lovell said about being able to control infection in herds and in valuable stock. As a woman who liked small domestic animals, she would have liked to have heard whether there was much infection among cats and dogs, because, to judge by their behaviour and passion, she would have expected all kinds of infections. She had wondered whether cats might have a brand of gonorrhœa.

Dr. T. E. Osmond desired to add his thanks to those of the others who had spoken; he did not remember when he had heard a paper which had interested him so much.

The references to llamas did not include Tibetan ones; but some years ago llama serum was about to be put on the market as it was considered to be a marvellous cure. Spirochætosis cuniculi was a source of trouble in laboratory work ; much of the laboratory work he carried out was ruined by it. If cuniculi were present in the infection it caused great difficulty with regard to human syphilis.

He asked whether dogs suffered from urethritis. His impression was that they did, but it might be they had only balanitis simulating urethritis. $\mathrm{He}$ would be glad to hear from Dr. Lovell concerning this.

DR. MARY LISTON remarked that she also had been very interested in Dr. Lovell's address, and in one point in it especially. He made reference to the virus of spirochætosis, and she would like to know what proof there was of a virus or toxin produced by spirochætes.

DR. LOVELL, in replying to the discussion, said that he very much appreciated the kind things which had been said about his paper. He feared his replies would not satisfy all the questioners.

Concerning the question on dourine, he knew little about its pathology, but for many years dourine had been known under the name of " horse syphilis," and whether that was because of its transmissibility by means of coitus, or because its pathology was similar to that of syphilis, he did not know. An indirect method of diagnosis such as the complement fixation test was necessary in dourine, for trypanosomes were so scanty in the blood that when from Ioo to 400 c.c. of blood from a suspected case was injected intra-peritoneally into dogs, trypanosomiasis did not always result. 


\section{VENEREAL DISEASES OF ANIMALS}

As to the trichomonad infection, there was either spontaneous recovery, or, if conception had taken place, pyometra developed and the animal became sterile. $\mathrm{He}$ was unable to say anything about the transmission of any of these diseases to offspring, but it must be noted that sterility occurred after some of them. With regard to trichomonad infection in the male, symptoms might or might not appear, but even when there were no symptoms the infection might be found. There were difficulties concerning control of the disease, but as the bull was the main source of infection some authors said that if a bull was proved to have infected one cow it was not safe to use that bull again for breeding.

He did not know anything about venereal diseases in cats ; in dogs the only disease transmitted during coitus that was well recognised in veterinary pathology was the venereal tumour.

He had been glad to hear the views on the allegations about veneral disease in the llama. He had found references to it in a French journal in I924 and I925, and if the story possessed any value he thought it would surely have been confirmed by now, and he was not aware of any confirmation.

As to Treponema cuniculi, it was regarded as specific to rabbits, and its importance lay in the fact that some of the experiments carried out with Treponema pallidum might be upset because of the spontaneous disease of rabbits.

He did not know how the spirochætes acted in producing ill effects, nor whether another factor was concerned, but he had been interested in the view put forward because there was the analogy of the Clostridium group of bacteria, in which a secondary factor was necessary before the organism could develop and produce its toxin. He could not say whether animals suffering from any of these diseases had nasal infection which might operate as a secondary factor. In animals latently infected with Brucella the organisms were found in the lymphatic system. As to the results of serological reactions as evidence of latent infection, it must be remembered that the Wassermann reaction was positive in many supposedly normal animals, and the reason for that was not understood. The Wassermann was not a true antigen anti-body reaction, but bore some relation 


\section{BRITISH JOURNAL OF VENEREAL DISEASES}

to the lipoid content of the " antigen." Many workers had endeavoured to elucidate its mechanism.

With regard to urethritis in dogs, that did occur, and it was largely of mechanical causation owing to drops of urine remaining in the prepuce, and often pus was present there. It began as a mechanical condition and infection developed later.

As to the question whether any of the diseases which had been described in his paper infected man, the only one on which he could be definite was Brucella infection. All types of Brucella might infect man, but infection took place largely by ingestion, though occasionally it might lake place through the skin or the conjunctiva, and many aboratory infections with these organisms had occurred. 